\title{
CD20-positive T-cell lymphoma involving bone marrow: report of four cases
}

\author{
Mayuko Imai • Jie-Gen Jiang • Zhao Wu • \\ Bashar Dabbas • Hongyu Ni
}

Received: 30 September 2012 / Accepted: 11 February 2013 /Published online: 26 February 2013

(C) Springer-Verlag Berlin Heidelberg 2013

Keywords T-cell lymphoma $\cdot$ Bone marrow

Lymphomas are classified based on clinical presentation, morphology, immunophenotyping and molecular studies. NonHodgkin lymphomas are broadly divided into B cell and T/NK cell types [1]. Historically, CD20 has been regarded as a specific B-cell marker and has been used to distinguish mature B-cell from T-cell neoplasms [2]. However, several reports have shown CD20 expression in peripheral T-cell lymphomas diagnosed in lymph nodes, skin lesions, mediastinal masses, adrenal masses, gastric lesions, and pancreatic masses [3-7]. In this report, we describe four patients with CD20positive T-cell lymphomas involving the bone marrow. Although little is known about the prognostic significance of CD20 expression in T-cell lymphomas, its identification may cause diagnostic difficulty. Therefore, a combination of morphologic examination, immunophenotypic analysis with a broad panel of antibodies, and molecular studies is necessary for determination of the cell lineage and making a correct diagnosis.

\section{Materials and methods}

Case selection

All four cases were identified during our diagnostic service at Genoptix Medical Laboratory.

M. Imai $\cdot$ J.-G. Jiang $\cdot$ Z. Wu $\cdot$ B. Dabbas $\cdot$ H. Ni

Genoptix Medical Laboratory, A Novartis Company, Carlsbad, CA 92008, USA

H. Ni $(\bowtie)$

Department of Pathology \& Laboratory Medicine,

Foothills Medical Center, University of Calgary,

Room C614C 1403-29 St NW,

Calgary, Alberta, Canada T2N 2T9

e-mail: hongyu.ni@cls.ab.ca
Histology and immunohistochemistry

All bone marrow specimens were fixed in $10 \%$ neutralbuffered formalin and embedded in paraffin. Bone marrow sections were stained with standard hematoxylin-eosin. Immunohistochemical staining of paraffin sections was performed using heat-induced epitope retrieval technique and a universal secondary antibody kit with peroxidaseconjugated complex using validated staining protocols.

Flow cytometric analysis

Flow cytometric analyses were performed in our laboratory using six-color flow cytometry on a FACSCalibur flow cytometer (BD Biosciences, San Jose, CA). Commercially available antibodies were purchased from BD Biosciences (San Jose, CA)

\section{Case report}

\section{Case 1}

An 82-year-old female without significant past medical history presented with pancytopenia. She did not have any B symptoms. Bone marrow examination was performed for the evaluation of a myelodysplastic syndrome (MDS). Accompanying $\mathrm{CBC}$ report indicated $\mathrm{WBC} 1.0 \mathrm{~K} / \mu \mathrm{L}, \mathrm{RBC} 2.97 \mathrm{M} / \mu \mathrm{L}, \mathrm{Hgb}$ $9.1 \mathrm{~g} / \mathrm{dL}, \mathrm{HCT} 26.1 \%$, MCV $88 \mathrm{fL}, \mathrm{MCH} 30.7 \mathrm{pg}$, MCHC $34.9 \mathrm{~g} / \mathrm{dL}$, red cell distribution width (RDW) $16.5 \%$, and platelets $38 \mathrm{~K} / \mu \mathrm{L}$. CT scan demonstrated no evidence of lymphadenopathy or hepatosplenomegaly. PET scan was negative.

Case 2

A 59-year-old woman with a history of diabetes mellitus presented with severe anemia, night sweats, weight loss of 
$20 \mathrm{lbs}$, and fever for several weeks. She had received blood transfusion. CT scan revealed mild splenomegaly with maximum splenic length of $15.6 \mathrm{~cm}$. PET scan demonstrated no hypermetabolic activity within the spleen. The $\mathrm{CBC}$ results showed WBC $11.5 \mathrm{~K} / \mu \mathrm{L}, \mathrm{RBC} 3.64 \mathrm{M} / \mu \mathrm{L}, \mathrm{Hgb} 10.1 \mathrm{~g} / \mathrm{dL}$, HCT $29.2 \%$, MCV 80.3 fL, MCH 27.7 pg, MCHC $34.5 \mathrm{~g} / \mathrm{dL}$, RDW $18.5 \%$, and platelets $34 \mathrm{~K} / \mu \mathrm{L}$. Bone marrow and peripheral blood specimens were submitted to rule out MDS.

\section{Case 3}

A 77-year-old male presented with pancytopenia, night sweats, and fever for several weeks. The CBC showed WBC $2.5 \mathrm{~K} / \mu \mathrm{L}, \mathrm{RBC} 2.76 \mathrm{M} / \mu \mathrm{L}, \mathrm{Hgb} 8.6 \mathrm{~g} / \mathrm{dL}$, HCT $25.7 \%$, MCV $93.3 \mathrm{fL}$, MCH $31.3 \mathrm{pg}$, MCHC $33.6 \mathrm{~g} / \mathrm{dL}$, RDW $17.7 \%$, and platelets $24 \mathrm{~K} / \mu \mathrm{L}$. A bone marrow study was performed to evaluate causes of cytopenia. CT scan showed no evidence of lymphadenopathy or hepatosplenomegaly. PET scan was negative.

\section{Case 4}

A 76-year-old female presented with lymphocytosis with no B symptoms. The CT scan was negative for lymphadenopathy and splenomegaly. PET scan was negative. The CBC indices showed WBC $54.8 \mathrm{~K} / \mu \mathrm{L}, \mathrm{RBC} 5.01 \mathrm{M} / \mu \mathrm{L}, \mathrm{Hgb}$ $14.5 \mathrm{~g} / \mathrm{dL}$, HCT $44.2 \%$, MCV $88.2 \mathrm{fL}, \mathrm{MCH} 28.9 \mathrm{pg}$, MCHC $32.8 \mathrm{~g} / \mathrm{dL}$, RDW $14.9 \%$, and platelets $267 \mathrm{~K} / \mu \mathrm{L}$ with a differential count of neutrophils $11.6 \%$, lymphocytes $81.6 \%$, monocytes $3.8 \%$, eosinophils $0.2 \%$, and basophils
$2.8 \%$. Peripheral blood and bone marrow studies were performed to evaluate causes of lymphocytosis.

\section{Results}

Clinical features

The cases included three females and one male, with a median age of 73.5 years old. Three patients had no clinical evidence of lymphadenopathy or extranodal lymphoma. One patient had mild splenomegaly. None of the four patients had a known history of lymphoma.

Histopathology findings

All four cases showed hypercellular marrow with interstitial lymphocytic infiltrates. The infiltrating lymphocytes were small- to medium sized with a small amount of cytoplasm, slightly irregular nuclei, and inconspicuous nucleoli (Fig. 1a, b). Large lymphocytes were not increased. The percentages of the lymphoma cells in the bone marrows were the following: case $1,60 \%$; case $2,80 \%$; case 3 , $70-80 \%$; and case $4,30-40 \%$.

\section{Immunophenotypic features}

Immunohistochemical stains of all four cases showed the infiltrating lymphocytes to be positive for $\mathrm{CD} 3$ and CD20, but negative for CD79a and PAX-5 (Fig. 1c, d). Of the four cases, cases 1, 2, and 4 expressed CD4, whereas case 3
Fig. 1 a Bone marrow aspirate illustrates small- to mediumsized lymphocytes (arrows) (Wright stain, original magnification $\times 500$ ). b Core biopsy shows hypercellular marrow with interstitial lymphocytic infiltrates (hematoxylin and eosin stain, original magnification $\times 200$ ). $\mathbf{c}$ The infiltrating lymphocytes are positive for CD20 (immunoperoxidase staining, original magnification $\times 200$ ). d The infiltrating lymphocytes are positive for $\mathrm{CD} 3$ (immunoperoxidase staining, original magnification $\times 200$ )

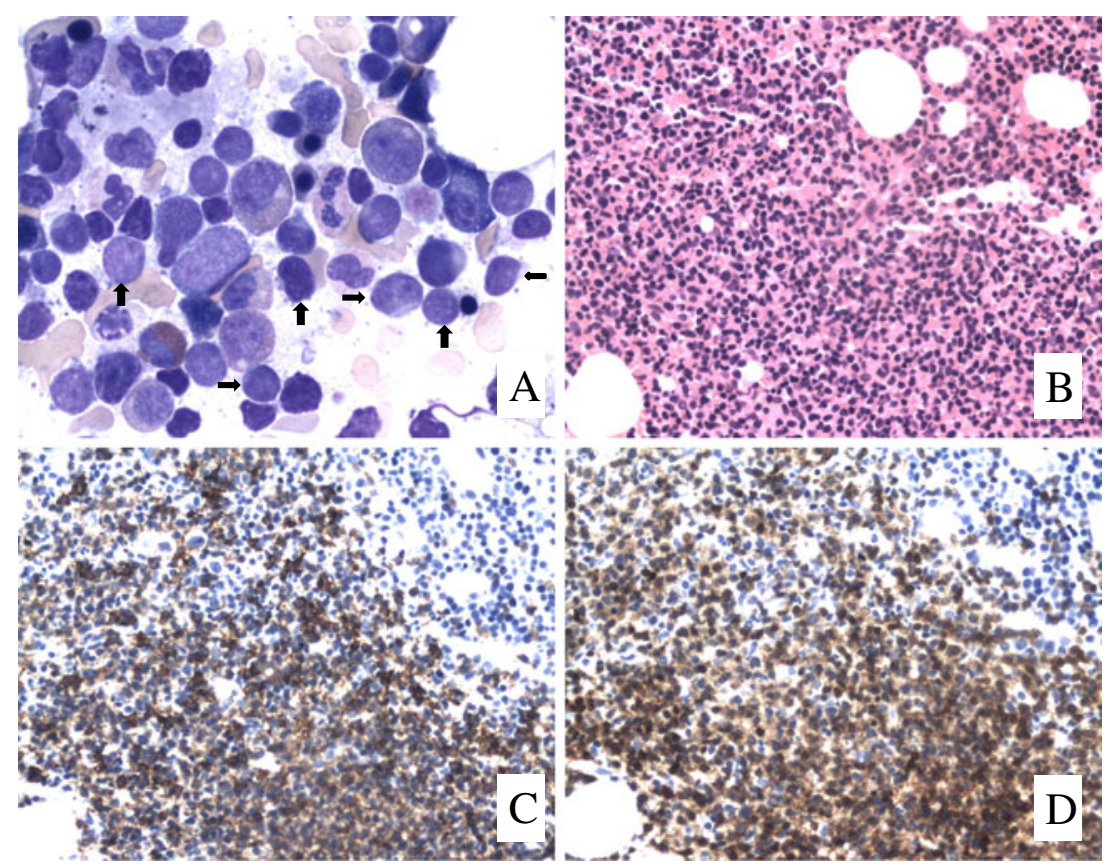


displayed positivity for $\mathrm{CD} 7$ and $\mathrm{CD} 8$, with decreased CD5 expression.

By six-color flow cytometric analysis, all cases expressed T-cell lineage markers and CD20 but were negative for other B cell-related antigens including CD19, CD22, and FMC7 (Fig. 2 and Table 1). In cases 1, 2, and 4, the lymphoma cells were positive for $\mathrm{CD} 2, \mathrm{CD} 3, \mathrm{CD} 4$, and $\mathrm{CD} 5$, with two cases lacked or partially lost CD7 expression (Fig. 2). The case three patient showed positive CD2, cytoplasmic CD3, CD7, and $\mathrm{CD} 8$, but negative for surface $\mathrm{CD} 3$ and $\mathrm{CD} 5$.

B-cell and T-cell gene rearrangement by PCR

B-cell gene rearrangement studies were performed on cases 2 and 4. Both cases were negative for clonal B-cell gene rearrangement. T-cell gene rearrangement analyses were performed on cases 1 and 4 . The first case showed no clonal T-cell gene rearrangement, while the case 4 was positive for both clonal T-cell beta and T-cell gamma gene rearrangements.

Epstein-Barr virus-encoded RNA in situ hybridization

EBER was negative for all four cases by in situ hybridization.

Cytogenetic and fluorescence in situ hybridization analysis findings

Three of the four cases demonstrated clonal cytogenetic changes. Cytogenetic analysis of case 1 showed an abnormal
Table 1 Summary of immunophenotypic findings in four cases of CD20-positive T-cell lymphoma

\begin{tabular}{lllll}
\hline Case number & 1 & 2 & 3 & 4 \\
Age (years)/sex & $82 /$ female & $59 /$ female & $77 /$ male & $76 /$ female \\
\hline CD45 & + & + & + & + \\
CD2 & + & + & + & + \\
Surface CD3 & + & + & - & + \\
Cytoplasmic CD3 & NA & NA & + & NA \\
CD4 & + & + & - & + \\
CD5 & + & + & - & + (bright) \\
CD7 & - & - & + & + \\
CD8 & - & - & + & - \\
CD10 & - & - & - & - \\
CD19 & - & - & - & - \\
CD16 & - & - & - & - \\
CD20 & + & $+($ dim) & + & + (dim) \\
CD56 & - & - & - & - \\
CD57 & - & - & - & - \\
CD22 & - & - & - & - \\
FMC7 & - & - & - & - \\
\hline
\end{tabular}

$N A$ not available

female karyotype including a deletion of the long arm of chromosome 6 and a deletion of the short arm of chromosome 12. Fluorescence in situ hybridization (FISH) analysis of case 3 revealed trisomy 7 and trisomy $14 q$ involving T-cell receptor
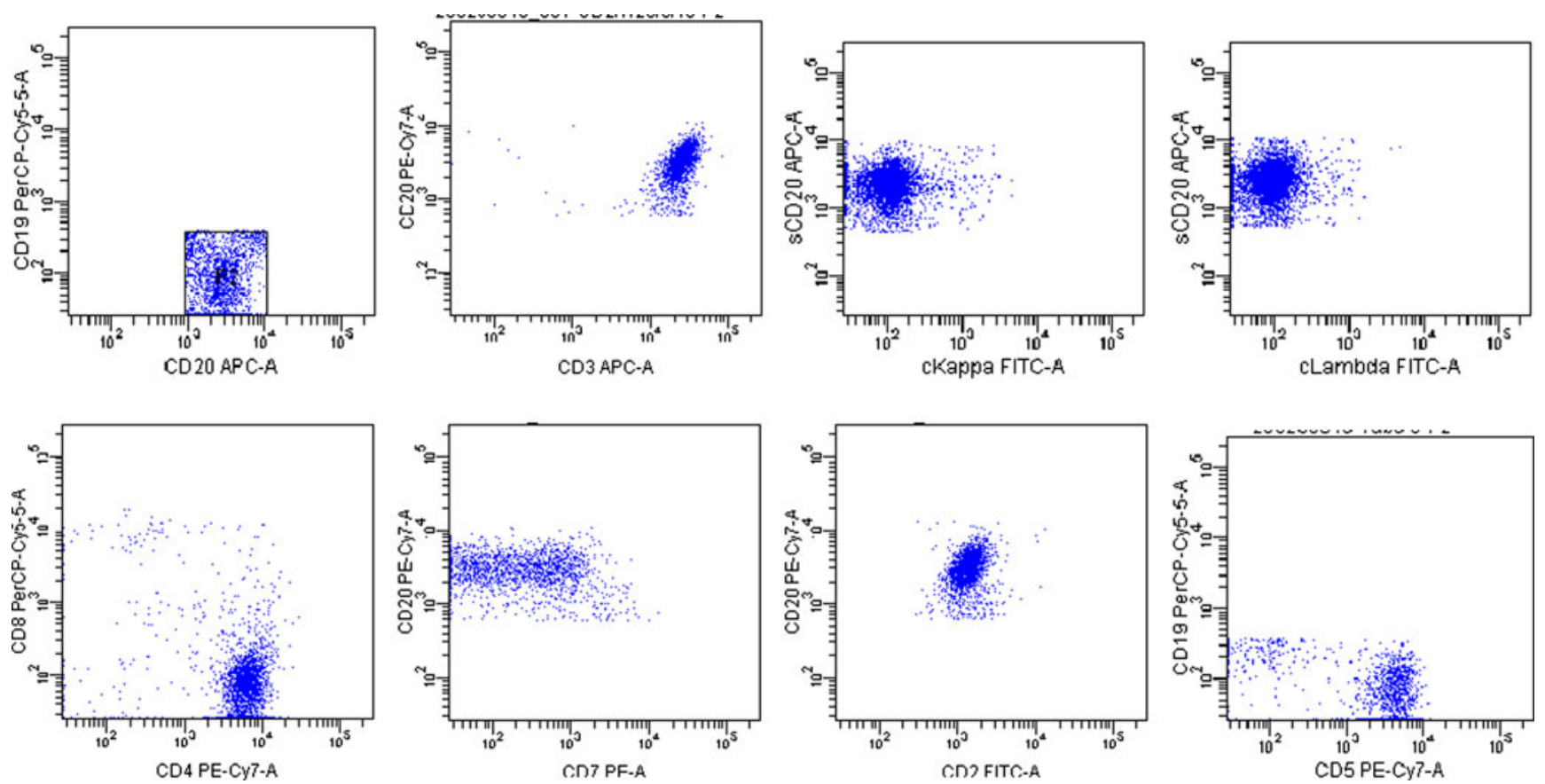

Fig. 2 Flow cytometric analysis of CD20-positive T-cell lymphoma. CD3-positive and CD20-positive T cells express CD2, CD4, and CD5, but not express CD8, CD19, and kappa or lambda light chains. The lymphoma cells show decreased CD7 expression 
alpha/delta locus. FISH analysis of case 4 showed deletion of 11q (ATM) gene.

\section{Discussion}

Expression of CD20 in T-cell lymphomas is a rare phenomenon that has been reported in the literature [8-10]. In previous reports, patients presented with lymphadenopathy, skin lesions, mediastinal masses, adrenal masses, gastric lesions, and pancreatic masses $[11,12]$. In the current report, we describe four cases of CD20-positive T-cell neoplasms involving bone marrow with one case showing both bone marrow and peripheral blood involvements. Three patients had no clinical evidence of lymphadenopathy or tissue mass lesions. One patient had mild splenomegaly. Bone marrow examinations were performed to evaluate causes of cytopenia in three cases. In the fourth case, the bone marrow was performed because of leukocytosis. All four cases showed hypercellular marrow with interstitial lymphocytic infiltrates consisting of small- to medium-sized neoplastic lymphoid cells. The T-cell lineage of these cases was established by the presence of multiple T-cell markers including $\mathrm{CD} 2, \mathrm{CD} 3, \mathrm{CD} 4, \mathrm{CD} 5$, and CD7. In all cases, neoplastic cells were positive for $\mathrm{CD} 20$, but negative for other B-cell antigens as demonstrated by both immunohistochemistry as well as flow cytometry. Two cases tested for B-cell gene rearrangement showed no evidence of clonal B-cell gene rearrangements. Flow cytometric analyses demonstrated no evidence of monoclonal B-cell populations. All four cases were diagnosed as peripheral T-cell lymphoma, unclassifiable, according to the 2008 WHO Classification [13]. The diagnosis was based on the bone marrow morphology, aberrant T-cell antigens, clonal cytogenetic abnormalities, and in one case, with clonal T-cell gene rearrangement. Review of the literature revealed that CD20-positive T-cell lymphomas have also been described in cases classified as anaplastic large cell lymphoma, lymphoblastic lymphoma, angioimmunoblastic T-cell lymphoma, T-cell prolymphocytic leukemia, mycosis fungoides, adult T-cell leukemia/lymphoma, and peripheral T-cell lymphoma, not otherwise specified $[11,12]$.

The pathogenesis of CD20-positive T-cell lymphoma is not known. CD20 is a transmembrane protein with a molecular weight of $37 \mathrm{kD}$ which was first identified as a B-cell marker in 1980 [14]. This protein appears early in B-cell development and remains through B-cell maturation to the plasma cell stage [15]. Therefore, this antigen has been regarded as a specific Bcell marker and has been used to designate B-cell lineage [16]. However, several reports have described small populations of T cells expressing CD20 in the peripheral blood and bone marrow in healthy individuals $[17,18]$. Hultin and colleagues described dim CD20 expression on CD3-positive T cells comprising $2.4 \pm 1.5 \%$ of peripheral blood lymphocytes [17]. It is possible that $\mathrm{CD} 20$-positive T-cell lymphomas may arise from the subpopulations of normal CD20-positive $\mathrm{T}$ cells that have undergone neoplastic transformation. An alternative hypothesis is that CD20-positive T-cell lymphomas represent an aberrant expression of $\mathrm{CD} 20$ as lineage infidelity. It is not uncommon for B-cell lymphomas to aberrantly express $\mathrm{T}$ cell-associated antigens, particularly CD5 and/or CD43. Such aberrant coexpression is often useful in distinguishing a neoplastic Bcell lymphoma from a reactive B-cell proliferation as well as in the subclassification of low-grade B-cell lymphomas [19].

Little is known about the prognostic significance of CD20 expression in T-cell lymphoma. Review of published literatures showed that among 14 cases with clinical follow-up, relapse, refractory disease, disease progression, or deaths were documented in ten cases [11]. A recent report described a CD20-positive T-cell lymphoma with an indolent clinical course. The patient had recurrent enlarged lymph nodes for 12 years [20]. In our current study, two patients (cases 2 and 3 ) received chemotherapy with $\mathrm{CHOP}$ regimen and responded poorly to the treatment. Both patients deceased several months after diagnosis. One patient (case 1) did not receive treatment and lost follow-up. Case 4 was doing well without any treatment for lymphoma at 3 months after the initial diagnosis when this manuscript was submitted. These studies suggest that the underlying diagnosis of T-cell lymphoma is likely the more important pathologic determinant of clinical behavior of CD20-positive T-cell lymphoma. CD20 expression may not be an important determinant of the prognosis. However, further clinical studies are needed to evaluate prognostic significance.

CD20 is the molecular target for monoclonal antibody therapy with Rituximab [21]. Treatment with Rituximab currently plays a major role in the management of B-cell non-Hodgkin lymphomas and autoimmune disorders [21]. The expression of CD20 on T-cell lymphoma may provide opportunities for treating the patients with CD20-targeted monoclonal antibodies (Rituximab). Rahemtullah et al. reported three patients with CD20-positive T-cell lymphoma who received Rituximab in addition to other chemotherapy agents [11]. The first patient relapsed and died at 16 months, and the second patient had recurrent disease at 10 months. In both patients, the lymphoma cells lacked CD20 expression at relapse, which could be attributed to Rituximab administration. The third patient was alive and undergoing treatment at 6 months after the initial diagnosis. Due to the small number of reported cases, the potential therapeutic benefit of Rituximab treatment remains unknown.

In this report, we have described four cases of CD20positive T-cell neoplasms involving bone marrow. Three patients demonstrated no clinical evidence of lymphadenopathy or extranodal lymphoma. Our studies suggest that bone marrow CD20-positive T-cell lymphomas may cause diagnostic difficulty. A combination of morphologic examination, immunophenotypic analysis with a broad panel of antibodies, and molecular studies is required to make a correct diagnosis. The recognition of CD20-positive T-cell 
lymphoma is important in providing appropriate therapy. Such aberrant antigen expression may be diagnostically useful in the detection of post-therapy minimal residual disease.

Conflict of interest The authors declare that they have no conflict of interest.

\section{References}

1. Camps E, Swerdlow SH, Harris NL, Pileri S, Stein H, Jaffe ES (2011) The 2008 WHO classification of lymphoid neoplasms and beyond: evolving concepts and practical applications. Blood 117:5019-5032

2. Foon KA, Schroff RW, Gale RP (1982) Surface markers on leukemia and lymphoma cells: recent advances. Blood 60:1-19

3. Buckner CL, Christiansen LR, Bourgeois D, Lazarchick JJ, Lazarchick J (2007) CD20 positive T-cell lymphoma/leukemia: a rare entity with potential diagnostic pitfalls. Ann Clin Lab Sci 37:263-267

4. Blakolmer K, Vesely M, Kummer JA, Jurecka W, Mannhalter C, Chott A (2000) Immunoreactivity of B-cell markers (CD79a, L26) in rare cases of extranodal cytotoxic peripheral T-(NK/T-) cell lymphomas. Mod Pathol 13:766-772

5. Warzynski MJ, Graham DM, Axtell RA, Zakem MH, Rotman RK (1994) Low level CD20 expression on T cell malignancies. Cytometry 18:88-92

6. Yao X, Teruya-Feldstein J, Raffeld M, Sorbara L (2001) Peripheral T cell lymphoma with aberrant expression of CD79a and CD20: a diagnostic pitfall. Mod Pathol 14:105-110

7. Kitamura A, Yamashita Y, Mori N (2005) CD20-positive cytotoxic T cell lymphoma: report of two cases and review of the literature. J Clin Exp Hematopathol 45:45-50

8. Quintanilla-Martinez L, Preffer F, Rubin D, Ferry J, Harris NL (1994) $\mathrm{CD}^{2} 0^{+} \mathrm{T}$ cell lymphoma, neoplastic transformation of a normal T cell subset. Am J Clin Pathol 102:483-489
9. Yokose N, Ogata K, Sugisaki Y, Mori S, Yamada T, An E, Dan K (2001) CD20-positive T cell leukemia/lymphoma: case report and review of the literature. Ann Hematol 80:372-375

10. Mohrmann RL, Arber DA (2000) CD20-positive peripheral T cell lymphoma: report of a case after nodular sclerosis Hodgkin's disease and review of the literature. Mod Pathol 13:1244-1252

11. Rahemtullah A, Longtine JA, Harris NL, Dorn M, Zembowicz A, Quintanilla-Fend L, Preffer FI, Ferry JA (2008) CD20 ${ }^{+}$T-cell lymphoma: clinicopathologic analysis of 9 cases and a review of the literature. Am J Surg Pathol 32:1593-1607

12. Miyazaki K, Ohsaka M, Suzuki Y, Danbara M, Horie R, Higashihara M (2009) CD20-positive T-cell large granular lymphocyte leukemia: case report and review of the literature. Intern Med 48:1443-1447

13. Pileri SA, Weisenburger DD, Sng I, Jaffe ES, Ralfkiaer E, Nakamura S, Müller-Hermelink HK (2008) Peripheral T-cell lymphoma, not otherwise specified. In: Swerdlow SH (ed) WHO classification of tumours of haematopoietic and lymphoid tissues, 4th edn. IARC Press, Lyon, pp 306-308

14. Stashenko P, Nadler LM, Hardy R, Schlossman SF (1980) Characterization of a human B lymphocyte-specific antigen. J Immunol 125:1678-1685

15. Tedder TF, Engel P (1994) CD20: a regulator of cell-cycle progression of B lymphocytes. Immunol Today 15:450-454

16. Nadler LM, Ritz J, Hardy R, Pesando JM, Schlossman SF, Stashenko P (1981) A unique cell surface antigen identifying lymphoid malignancies of B cell origin. J Clin Invest 67:134-140

17. Hultin L, Hausner M, Hultin P, Giorgi J (1993) CD20 (pan-B cell) antigen is expressed at a low level on a subpopulation of human $\mathrm{T}$ lymphocytes. Cytometry 14:196-204

18. Algino KM, Thomason RW, King DE, Montiel MM, Craig FE (1996) CD20 (pan-B cell antigen) expression on bone marrowderived T cells. Am J Clin Pathol 106:78-81

19. Swerdlow SH (1999) Small B-cell lymphomas of the lymph nodes and spleen: practical insights to diagnosis and pathogenesis. Mod Pathol 12:125-140

20. Xiao W, Wang Z, Wang L (2010) CD20-positive T-cell lymphoma with indolent clinical behavior. J Int Med Res 38:1170-1174

21. Beers SA, Chan CHT, French RR, Cragg MS, Glennie MJ (2010) CD20 as a target for therapeutic type I and II monoclonal antibodies. Semin Hematol 47:107-114 